\title{
Cerebral Empyema Complicating a Dental Abscess
}

Lazraq mohamed ${ }^{1 *}$, Bensaid abdelhak ${ }^{2}$, Miloudi youssef ${ }^{3}$, and Elharrar najib ${ }^{4}$.

${ }^{1}$ Department of Anesthesia-Resuscitation, Hospital August 20, 1953, UHC Ibn Rochd of Casablanca, Morocco.

${ }^{2}$ Associate Professor in Anesthesia-Resuscitation, Hospital August 20, 1953, UHC Ibn Rochd of Casablanca, Morocco.

${ }^{3}$ associate professor in anesthesia-intensive care, Hospital August 20,1953, UHC Ibn Rochd of Casablanca, Morocco.

${ }^{4}$ Associate Professor in Anesthesia-Resuscitation, Hospital August 20, 1953, UHC Ibn Rochd of Casablanca, Morocco.

*Corresponding Author : Lazraq Mohamed, Study undertaken in the Department of Anesthesia-Resuscitation, Hospital, Morocco.

Email: mohamed_lz@hotmail.com

Received date: March 19,2019;Accepted date : April 15,2019; Published date: April 24,2019.

Citation: Lazraq mohamed, Bensaid abdelhak, Miloudi youssef, and Elharrar najib. Cerebral Empyema Complicating a Dental Abscess. j. General medicine and clinical practice. Doi: http://dx.doi.org/ 10.31579/ 2639-4162/2019/030.

Copyright : (c) 2019 Lazraq mohamed. This is an open-access article distributed under the terms of The Creative Commons Attribution License, which permits unrestricted use, distribution, and reproduction in any medium, provided the original author and source are credited.

\begin{abstract}
Cervico-facial cellulitis can cause serious complications including neuro-meningeal infections. Among these neuro-meningeal infections are intracranial empyemas, which are rarer than brain abscesses. We report the case of a young patient of 25 years, immunocompetent, having presented a cerebral empyema secondary to diffuse cervicofacial cellulitis of dental origin. The diagnosis was suspected in the presence of cervicofacial cellulitis, febrile meningeal syndrome and consciousness disorder, confirmation was reported by brain MRI. The evolution was favorable after the recourse to the surgical treatment.
\end{abstract}

Keywords: dental abscess; cellulitis; cerebral empyema

\section{Introduction}

Cervico-facial cellulitis is a severe infection of the subcutaneous cellular tissue of the face and is most often of dental or peridental origin. It can be at the origin of serious complications including neuromeningeal infections [1].

Although it is a rare complication, especially in young adults who are incompetent [7-8], it remains serious and may be life-threatening.

Cerebral abscesses are preferentially located in the parietal or frontal lobe $[2,3]$. Intracranial empyemas are rarer than cerebral abscesses, account for $25-31 \%$ of intracranial suppurations [4], $75 \%$ being subdural $[5,6]$

We report in this paper the case of a patient who developed a subdural empyema secondary to diffuse cellulitis of dental origin in a 25-yearold boy.

\section{Observation}

This is a 25-year-old patient with no pathological history, admitted to otorhinolaryngological emergencies for cervicofacial cellulitis. The symptomatology was two weeks earlier by the appearance of a dental abscess initially treated with a nonsteroidal anti-inflammatory drug and a spiramycin antibiotherapy. The evolution was marked by the appearance of a red and hot swelling in the cervicofacial and temporal region.

At admission, the patient was confused, Glasgow score at 14/15, without deficit, symmetrical and reactive pupils, hemodynamically stable and respiratory, feverish at $40{ }^{\circ} \mathrm{C}$, the clinical examination objectified a neck stiffness.

The cranio-cervicofacial scan showed left cervicofacial and temporal cellulitis with deep oro-phrayngeal, para-pharyngeal and left infratemporal region, with no detectable brain injury(image1)

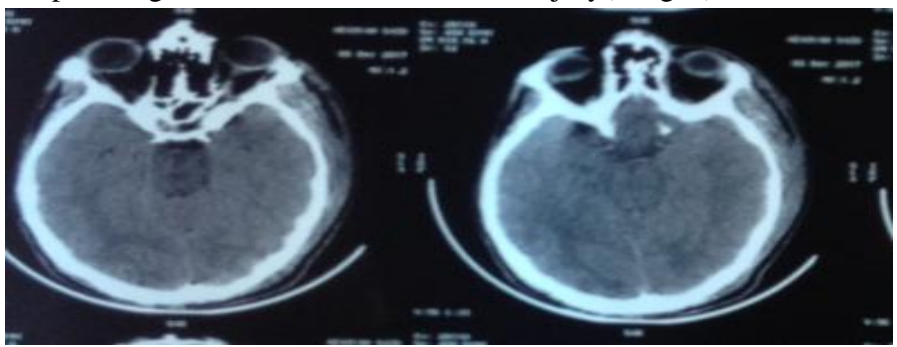

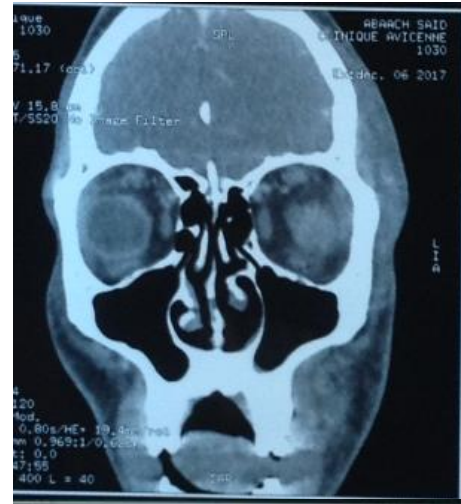
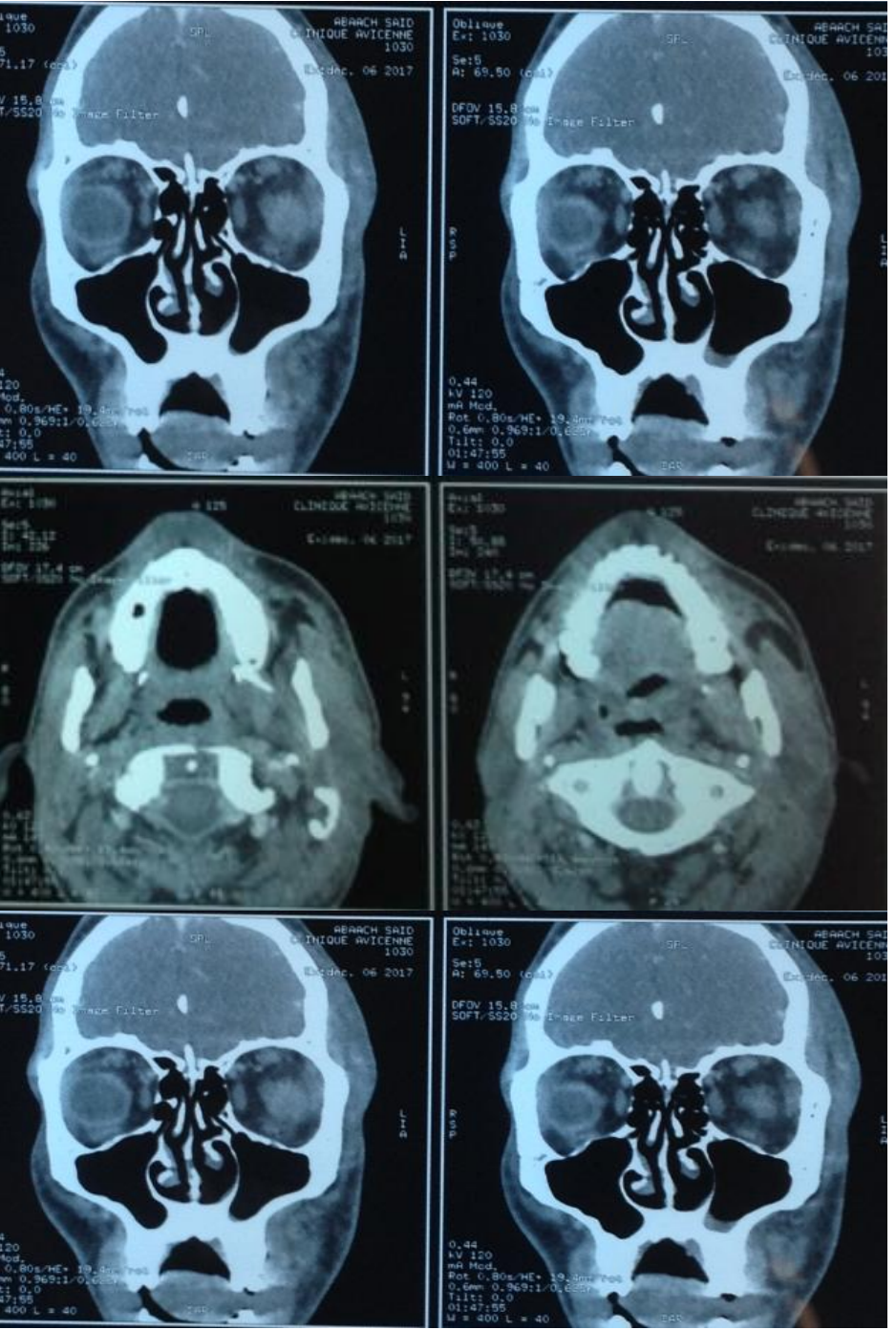

Auctores Publishing - Volume1-030 www.auctoresonline.org Page - 01 


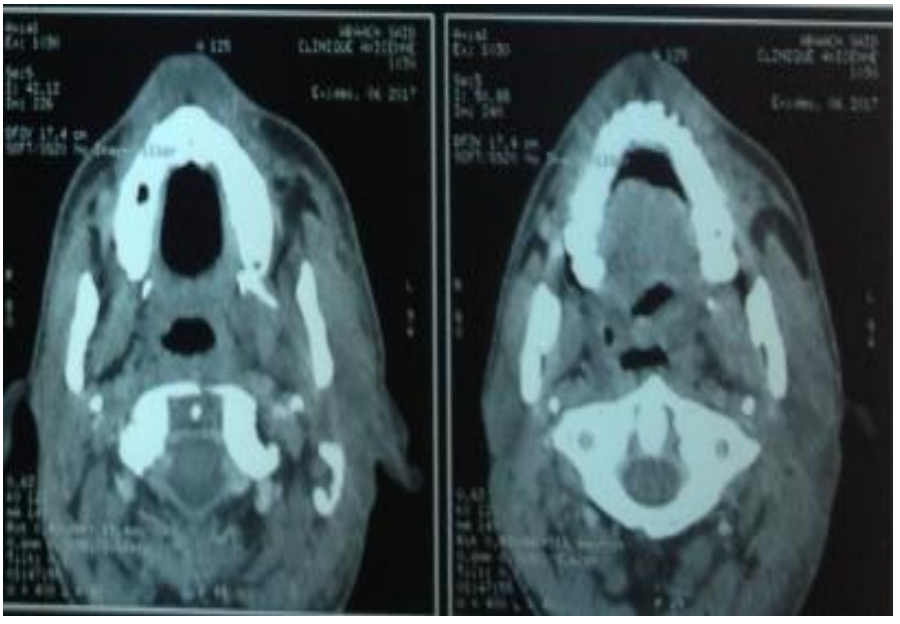

Image 1: Cervicofacial and left temporal cellulitis with deep collection oro-phrayngeal, para-pharyngeal and infra-temporal left.

The lumbar puncture was in favor of bacterial meningitis. The patient underwent surgical drainage of cellulite with tri-antibiotherapy based on ceftriaxon (meningeal dose), metronidazole and moxifloxacin. It should be noted that the immunological assessment of the patient was normal and the HIV serologies were negative. Bacteriological examination of pus revealed a multisensitive streptococcus SPP.

On day 2 of hospitalization, the patient presented generalized tonicclonic convulsions, which necessitated the realization of a cerebral MRI showing left subdural temporo-parietal empyema with diffuse enhancing meningeal (image 2).

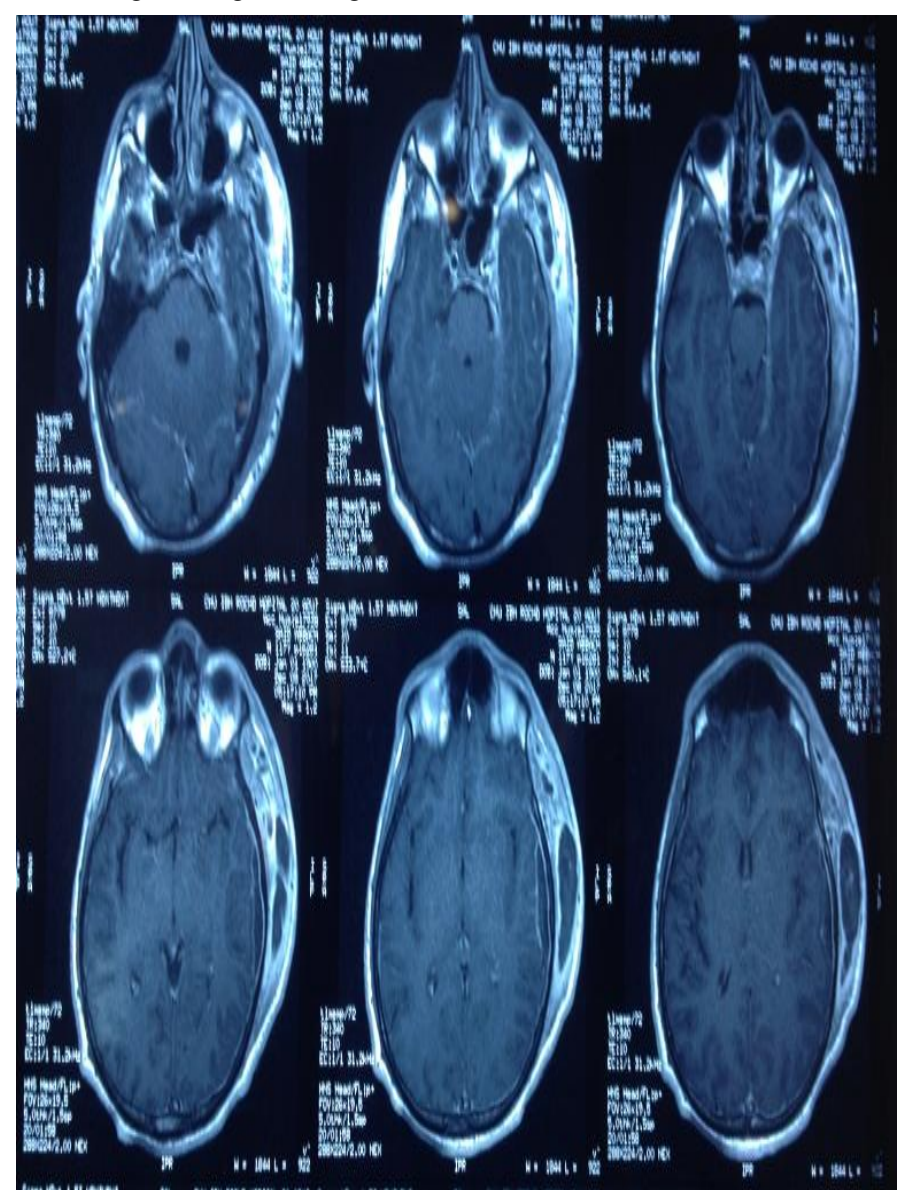

Image 2: left Cervico-facial cellulitis collected + left under dural empyema temporoparietal.

One week later, the patient experienced an alteration of his neurological status with control MRI worsening the left temporoparietal subdural empyema (image 3).

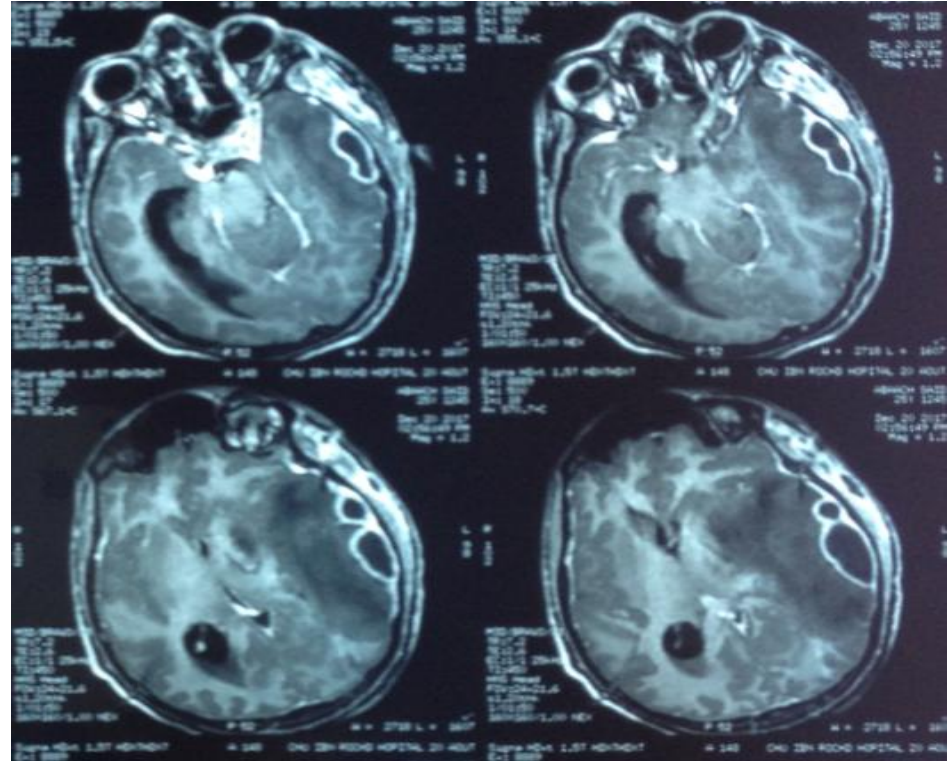

Image 3: Left temporoparietal empyema (17 mm thick), significant perilesional edema with mass effect and involvement under left temporal falciparum

Surgical drainage of the empyema was performed with a favorable evolution. The bacteriological examination of pus also objectified the same germ which is streptococcus spp multi-sensitive.

\section{Discussion}

Serious cellulitis is a serious infectious emergency especially in developing countries [9].

The mortality rate is high when effective management is not undertaken $[9,10]$. Inadequacy of primary treatment (inadequate antibiotic therapy and use of nonsteroidal anti-inflammatory drugs for analgesic purposes) is used as an adverse factor for the occurrence of serious infectious complications.

The diffuse cellulitis complications are numerous and serious (pleuropulmonary infection, mediastinal, thrombophlebitis, cerebral abscess ...). The prevalence of a dental infection for cerebral infections ranges from $2.7 \%$ to $6.5 \%$ [11].

The diffusion of the oral germs at the cerebral level can be made by contiguity within the framework of an acute infection or then by hematogenous way with the chronic foci [10]. The microbial flora found in cerebral abscesses of dental origin is polymorphic. In $70 \%$ of cases, we find streptococci [12], which is the case in our patient.

Cerebral abscess is thought to be the consequence of hematogenous dissemination of dental infection via the facial and ophthalmic veins where the germs enter the skull through the cavernous sinus $[13,14,15]$.

In fact, the known dental sources of cerebral infections include tooth abscess, cellulitis, periodontitis, extractions, canal treatments, and the placement of orthodontic appliances [16-17].

Bacteriologically, the most frequently responsible germs are streptococci and particularly those of the intermedius group, including Streptococcus anginosus [18].

Brain empyemas may be polymicrobial ( $40 \%$ of cases), especially if the germs originate from the oropharynx (association of streptococci and anaerobes). Other bacteria can also be found, depending on the portal of entry: enterobacteria, pyocyanic, staphylococcus aureus [18].

However, in each case where a dental origin is suspected, the eradication of infectious foci must be rigorous and must leave no room for doubt.

Regarding the cerebral infection, the classical treatment, included an urgent surgical evacuation supervised by an antibiotherapy, with a systematic size of a large shutter allowing a washing and a sufficient drainage of the empyema and the purulent cavities which are often compartmentalized by distance $[19,20,21]$. 
Currently, the latest generation antibiotics allow medical treatment without surgery, in the same way as the entryway treatment, and for up to 3 months $[22,23]$.

Antibiotic therapy is chosen with reference to isolated germs in the empyema and in the entryway. The surgical procedure is however necessary if the volume of the empyema determines signs of intracranial hypertension or if it increases in volume. It can be limited to the holes of trephine opposite the collection, or a large craniotomy allowing the complete evacuation of empyema, primary infectious foci and possibly verification of the absence of other localizations at different stages of the brain [20,24]. After collection evacuation, a drainage installation for a few days was often recommended by the authors $[20,25]$.

\section{Conclusion}

Indeed, the cerebral infectious localizations are certainly rare but providers of an important morbi-mortality, even if in our case the evolution was completely satisfactory. Intracranial suppurations constitute a medico-surgical emergency and their optimal management is a multidisciplinary collaboration (reanimateur, neurosurgeon, otolaryngologist, bacteriologist, radiologist...). otorhinolaryngological pathology remains the main entry point of these affections.

The diagnosis is based on the clinic and the radiology. The scanner is the first-line examination, it allows to make the diagnosis, to guide the therapeutic behavior and to follow the evolution. MRI sometimes performs better than CT. Sterile cultures have become increasingly common due to the early prescription of antibiotics. The prevention of these dreadful complications is based essentially on the eradication of infectious otorhinolaryngological and especially dental foci.

\section{Bibliography}

1. Goodkin HP, Harper MB, Pomeroy SL ( 2004). Intracerebral abscess in children: historical trends at Children's Hospital Boston. Pediatrics.,113(6):1765-70.

2. PAO-TSUAN KAO, HIANG-KUANG TSENG, CHANG-PAN LIU, SHEY-CHIANG SU, CHUN-MING-LEE. (2003) Brain abscess: clinical analysis of 53 cases. J Microbiol Infect , 36 : 129-136.

3. PRAZUCK T. Abcès cérébraux (2001).aspects cliniques, thérapeutiques, facteurs pronostiques Pyrexie, , 5 : 139-144.

4. LOEMBE P.M, OKOME-MONAKOU M, ALLIEZ. (1997). Les suppurations et empyèmes intracrâniens en milieu africain Méd Trop ; 57 : 186-194.

5. ALLIEZ B, DUCOLOMBIER A, GUEYE L.z (1992). Les suppurations collectées intracrâniennes : étude de 64 observations anatomocliniques. Méd Afr Noire ; 39 (5) : 377-82.

6. LEYS D, PETIT H ( 1994). Abcès cérébraux et empyèmes intracrâniens. Editions Techniques, Encycl Méd Chir Neurologie, 17-485-A-10, 6p.

7. Christine E. Hibberd, BA (Hons), DMD, Trang D. Nguyen, DDS. (2012). Abcès cérébral consécutif à une infection dentaire chez un garçon de 11 ans : une étude de cas. J Can Dent Assoc;78:c49_f

8. Goudot P, Mondjo JM, Larmande JM Dalens H, Grillo C, and Péri G. et al ( 1986). Abcès intracérébral d'origine dentaire chez un enfant. Rev Stomatol Chir Maxillofac. 85 : 115-8
9. Keita M, Doumbia K, Diango D, Diallo M, and Timbo Sk. et al. ( 2008). La cellulite cervical extensive en milieu hospitalier subsahélien une pathologie oubliée ? Cas du Mali. Médecine d'Afrique Noire - 55 (8-9) pp 464-470.

10. Diallo R, Balden. M, Conde B, Camara S.A.T, and Bah A.T. et al. (2006). Les cellulites cervico-faciales chez le patient diabétique au CHU de Conakry. Rev.Col. Odonto-Stomatol. Afr. Chir. Maxillofac., Vol. 13, n 3, , pp. 13-16.

11. P. Revol, A. Gleizal, T. Kraft, P. Breton, and M. Freidel14, et al. (2003). Abcès intracérabral et cellulite cervico-faciale diffuse. Complications d'une extraction de dent de sagesse: à propos d'un cas. Rev Stomatol Chir Maxillofac; 104, 5, 285-289.

12. Gendron R, Grenier D, Maheu-Mobert L (2000). The oral cavity as a reservoir of bacterial pathogens for focal infections. Microb Infect;2:897-906.

13. Zhang J, Stringer MD. (2010). Ophthalmic and facial veins are not valveless. Clin ExperimentOphthalmol. 38(5):502-10. Epub 2010 May 10

14. Baker SB, Weinzweig J, Bartlett SP, Whitaker LA (1999). Brain abscess as a complication of orthognathic surgery: diagnosis, management and pathophysiology. Plast ReconstrSurg.; 104 (2): 4802.

15. Erickson SJ, Hendrix LE, Massaro BM, Harris GJ, and Lewandowski MF, et al. (1989). et al. Color Doppler flow imaging of the normal and abnormal orbit. Radiology.; 173 (2): 511-6.

16. Azenha MR, Homsi G (2011). Garcia IR Jr. Multiple brain abscess from dental origin: case report and literature review. Oral MaxillofacSurg. [Epubaheadprint].

17. Gilon Y, Brandt L, Lahaye T, Heymans O (2002). Infections hématogènes d'origine dentaire. Rev Stomatol Chir Maxillofac , 103 :26-9

18. Wispelwey B (1997) Brain abscess in infections of the central nervous system. In: Scheld WM et al.,ed. Philadelphia: LippincottRaven;463-491 (2e éd.).

19. Bannister G, Willams B, Smith S. (1981) Treatement of sudural empyema. J. Neurosurg; 55: 85-8.

20. Cuddenec Y, Poncet J.L, Verdalle P, Buffe P. (1995). Complications locorégionales des otites. Encycl Med Chir Oto-rhino-laryng ; 20135-A-10:12p.

21. Emery E, Redondo A, Berthelot J.L, Bouali I, and Ouahes O, et al. (1999). Abcès et empyémes intracrâniens : prise en charge neurochirurgicale. Ann Fr Anesth Réan; 18: 567-73.

22. BOK A.P, PETER J.C. (1993). Subdural empyema: burr holes or craniotomy? A retrospective computerized tomography-ERA.

23. Analysis of treatement in 90 cases. J Neurosusrgery; $78: 574-78$.

24. Gilain L, Manipoud P. (2009). Complications crâniennes et endocrâniennes des infections nasosinusiennes. Encycl Méd Chir Oto-rhino-laryng; 20-445-A-10: 6p.

25. Nathoo N, Nadvi S.S, Van Dellen J.R, Gouws E. (1999). Intracranial subdural empyema in the era of computed tomography : A review of 699 cases. Neurosurg; 44 (3): 529-36.

26. Wackym P.A, Canalis R.F, Fuermant T. (1990 ). Subdural empyema of otorhinological origin. J Laryngol; 104 : 118-22. 